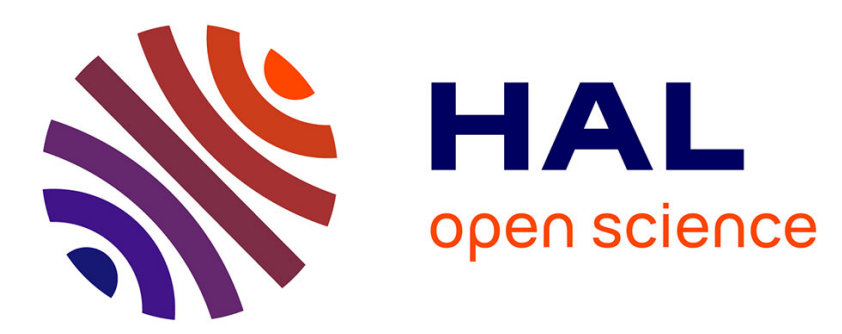

\title{
Sensory training with vibration-induced kinesthetic illusions improves proprioceptive integration in patients with Parkinson's disease
}

Edith Ribot-Ciscar, Jean-Marc Aimonetti, Jean-Philippe Azulay

\section{- To cite this version:}

Edith Ribot-Ciscar, Jean-Marc Aimonetti, Jean-Philippe Azulay. Sensory training with vibrationinduced kinesthetic illusions improves proprioceptive integration in patients with Parkinson's disease. Journal of Neurological Sciences, 2017. hal-01796040

\section{HAL Id: hal-01796040 \\ https://hal-amu.archives-ouvertes.fr/hal-01796040}

Submitted on 18 May 2018

HAL is a multi-disciplinary open access archive for the deposit and dissemination of scientific research documents, whether they are published or not. The documents may come from teaching and research institutions in France or abroad, or from public or private research centers.
L'archive ouverte pluridisciplinaire $\mathbf{H A L}$, est destinée au dépôt et à la diffusion de documents scientifiques de niveau recherche, publiés ou non, émanant des établissements d'enseignement et de recherche français ou étrangers, des laboratoires publics ou privés. 


\section{Sensory training with vibration-induced kinesthetic illusions improves}

\section{proprioceptive integration in patients with Parkinson's disease}

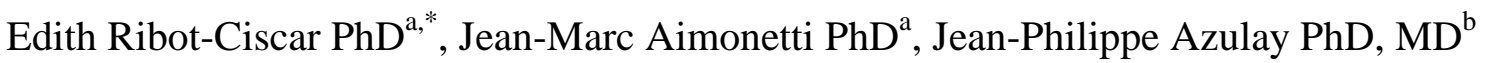

a Aix Marseille Univ, CNRS, LNIA, FR3C, Marseille, France

b APHM, Hôpital de la Timone, Service de Neurologie et pathologie du Mouvement, 13385

Marseille, France

Correspondence: E. Ribot-Ciscar, UMR 7260, Neurosciences Intégratives et Adaptatives - SFR 3C

3, Place Victor Hugo, 13331 Marseille Cedex 3, France.

E-mail address: edith.ribot-ciscar@univ-amu.fr

Keywords: proprioception, vibration, illusory movement, training, voluntary movement 


\section{Abstract:}

The present study investigates whether proprioceptive training, based on kinesthetic illusions, can help in re-educating the processing of muscle proprioceptive input, which is impaired in patients with Parkinson's disease (PD).

The processing of proprioceptive input before and after training was evaluated by determining the error in the amplitude of voluntary dorsiflexion ankle movement $\left(20^{\circ}\right)$, induced by applying a vibration on the tendon of the gastrocnemius-soleus muscle (a vibration-induced movement error). The training consisted of the subjects focusing their attention upon a series of illusory movements of the ankle.

Eleven PD patients and eleven age-matched control subjects were tested. Before training, vibration reduced dorsiflexion amplitude in controls by $4.3^{\circ}(P<0.001)$; conversely, vibration was inefficient in PD's movement amplitude (reduction of $2.1^{\circ}, P=0.20$ ). After training, vibration significantly reduced the estimated movement amplitude in PD patients by $5.3^{\circ}(P=0.01)$.

This re-emergence of a vibration-induced error leads us to conclude that proprioceptive training, based on kinesthetic illusions, is a simple means for re-educating the processing of muscle proprioceptive input in PD patients. Such complementary training should be included in rehabilitation programs that presently focus on improving balance and motor performance. 


\section{Introduction}

Muscle proprioceptive information is known to be of prime importance in the sense of posture and movement, and in the regulation of motor activities $(1,2)$. This peripheral muscle feedback seems to be spared in patients with Parkinson's disease (PD), as found through microneurographic recordings of muscle proprioceptive afferents (3). By contrast, the central treatment of this sensory feedback is impaired in PD patients as shown, for example, by the higher threshold for detecting passive movements (4,5), localization errors in hand position matching tasks (6), and in altered proprioception-related evoked potentials during passive movements (7). Changes in the supraspinal processing of proprioceptive input in PD have been demonstrated by analyzing the effect of mechanical vibration applied to the tendon of a muscle stretched during voluntary movements $(8,9)$.

Vibratory stimulation activates muscle spindle afferents, particularly primary endings (10), where the muscle feedback is not only related to the movement performed, but also to the vibration-induced response. In healthy subjects, this increased feedback changes the sense of movement, where the subject has an impression that the movement was performed at a higher velocity, leading to a reduction in the amplitude of the desired movement and a vibration-induced movement error $(11,12)$. In PD patients, this vibration-induced error is decreased, which indicates an altered processing of proprioceptive sensory information $(8,9)$. Changes in the cerebro-basal ganglia loop are thought to be responsible for this altered proprioceptive integration (4). The defective utilization of such proprioceptive information contributes to the movement issues that characterize this disease, notably in terms of postural control $(13,14)$. Thus, any therapy that could alleviate kinesthetic deficits may be considered important in the treatment of these patients (15).

The present study aimed at improving the integration of muscle proprioceptive inputs by supraspinal structures. For that purpose, PD patients and age-matched healthy subjects completed a training task during which they were asked to focus their attention upon illusory movements that were induced by 
muscle tendon vibration, in order to identify the illusory direction and velocity. The effect of the training was evaluated by measuring the vibration-induced movement error, as previously described, and we hypothesized that this error would increase after training, only in PD patients, indicating a better use of muscle proprioceptive cues in the perception of ankle movements. 


\section{Materials and Methods}

\subsection{Subjects}

Eleven patients with PD (range 50-73 years; mean \pm SD, 63.2 \pm 6.2 years; six females), all of whom had stimulating electrodes implanted bilaterally in the subthalamic nucleus, and 11 healthy subjects with no history of neurological or psychiatric disease (range 55-72 years; mean $\pm \mathrm{SD}, 63.3 \pm 4.9$ years; four females) participated in this study. All patients were tested on their regular antiParkinsonian medications and with the deep brain subthalamic nucleus stimulation turned on, providing optimal conditions to reduce bradykinesia $(6,15)$. Details of the clinical characteristics and basic demographics of the PD patients are listed in Table 1. The study was approved by the local ethics committee and all subjects provided their written, informed consent for the participation in the study.

\subsection{Experimental design and protocol}

The subjects lay on their back on a comfortable massage table with their feet unsupported. A goniometer was placed on the left foot in healthy subjects, or the foot on the more severely affected side in PD patients, at the level of the malleolus and a mechanical vibrator was positioned on the distal tendon of the gastrocnemius/soleus (GS) muscles; both were kept in place by means of Velcro elastic bands (Fig. 1). At the beginning of the experiment, the subjects experienced a few trials of vibratory stimulation to familiarize them with the equipment used and the sensations of illusory movement.

The subjects were asked to perform active dorsiflexion movements. The movement was first given to the subjects by the experimenter passively moving the ankle joint. The movement consisted of a dorsiflexion of $20^{\circ}$ for $2 \mathrm{~s}$, with a beginning and stop signal given by two warning beeps before returning to the starting angle, which was the subject's own anatomically neutral ankle position. The experimenter imposed the same movement five times and the subjects had to focus on both the 
amplitude and velocity of the movement. The subjects were then asked to reproduce the same movement as accurately as possible three times, with verbal feedback on their performance. After this stage of motor learning, voluntary movements were performed under their own proprioceptive guidance exclusively and no feedback was given on the performance. Three experimental sessions were run: pre-training, training, and post-training. In all sessions, the subjects were required to keep their eyes closed.

The pre- and post-training sessions consisted in 30 dorsiflexions that were voluntarily performed by the subjects either in the absence (non-vibrated, $N V, N=15$ ) or in the presence (vibrated, $\mathrm{V}, \mathrm{N}=15$ ) of GS tendon vibration, and the vibrations were conducted in a random order. During these trials, the end ankle angle reached at the stop auditory cue was measured (see Fig. 1). Data were recorded using a portable PowerLab system (ADInstruments, New Zealand). After each movement, the subjects rested for $30 \mathrm{~s}$.

In the training session, a second vibrator was placed on the tendon of the tibialis anterior (TA) muscle. The subjects were asked to remain totally relaxed and to focus their attention on the sensation of movement. A series of 40 trials were conducted where illusory movements of the ankle were elicited by activating either the $\mathrm{GS}(\mathrm{N}=20)$ or TA $(\mathrm{N}=20)$ vibrating stimulator, in random order. In 10 of these 20 trials, the GS vibratory stimulation was paired with a slow $1^{\circ}$ manual stretching of the GS muscle, by the experimenter, in order to increase the velocity of the sensation of illusory dorsal flexion movement. Likewise, in 10 of the 20 trials with TA vibratory stimulation, a slow $1^{\circ}$ manual stretching of the TA muscle was imposed to increase the velocity of the sensation of illusory plantar flexion movement. Immediately after each trial, the subjects were asked to verbally report both movement direction (dorsiflexion or a plantar flexion) and whether the perceived movement was of low (no stretching) or high (with stretching) velocity. All the participants (PD and control) felt clear sensations of illusory movement of the ankle joint and the parameters (direction and velocity) were as expected: a dorsiflexion or a plantar flexion when vibration was applied to the 
tendon of the GS or TA, respectively. Furthermore, for all the participants (PD and control) the velocity was perceived higher during the trials where a $1^{\circ}$ stretching of the vibrated muscle was added.

\subsection{Mechanical vibration}

Vibrations (frequency: $80 \mathrm{~Hz}$; peak-to-peak amplitude: $0.5 \mathrm{~mm}$ ) were delivered via mechanical vibrators (DC motors with eccentric masses, $1.5 \mathrm{~cm}$ in diameter, $4 \mathrm{~cm}$ in length, Technoconcept, France).

In the pre- and post-training sessions, during the $\mathrm{V}$ trials, vibration lasted for $2 \mathrm{~s}$, i.e. the GS vibrator was turned on and off, on the go and stop auditory cues, respectively. In the training session, the GS or TA vibrator was activated during 8 s, i.e. a time sufficient to induce a clear sensation of ankle movement, but not for too long so as to prevent disagreeable sensations such as exaggerated plantar flexion displacements.

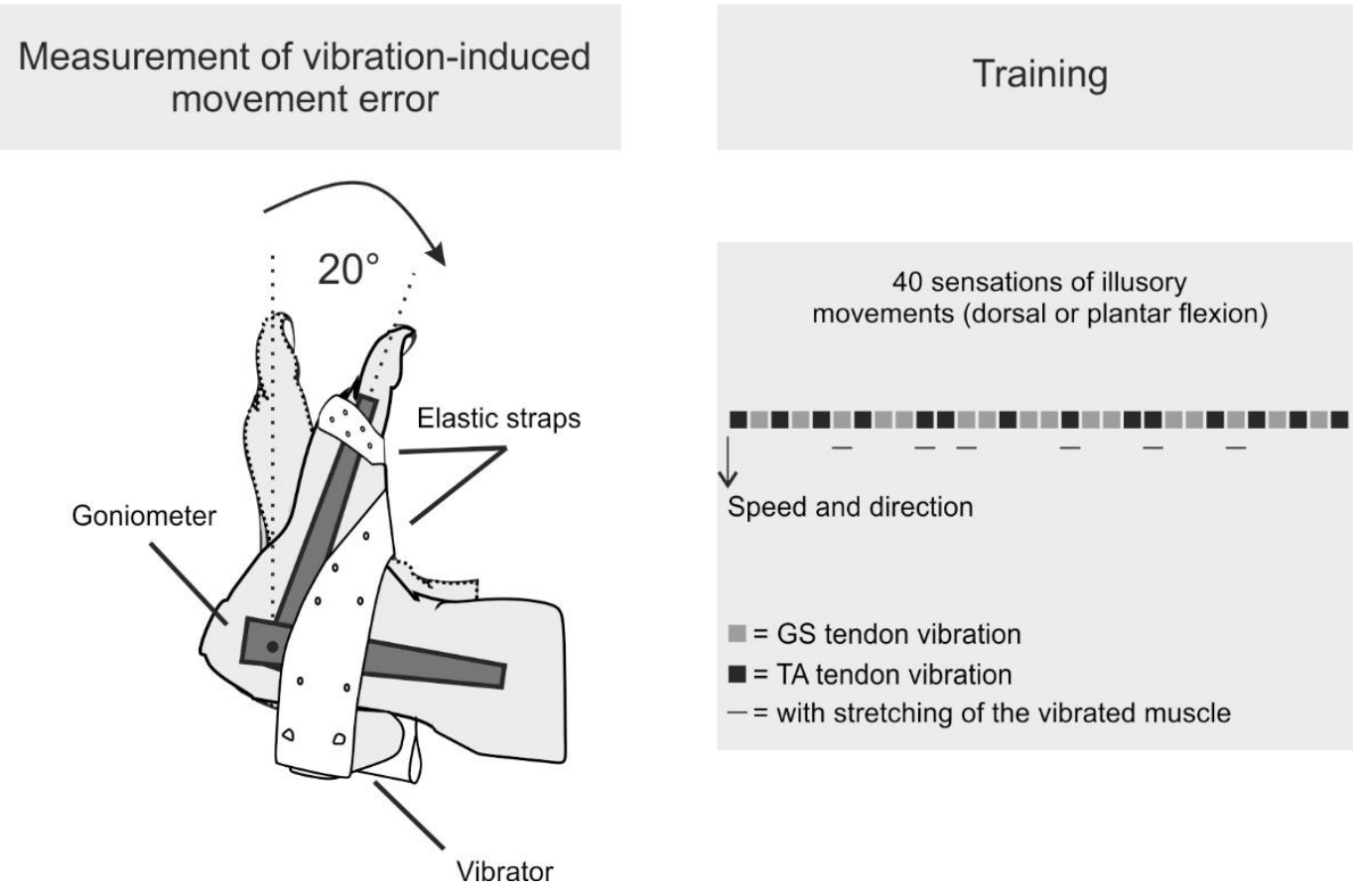

Fig. 1: Diagram of the experiment. 
The movement amplitudes measured without and with vibratory stimulation were compared before and after the training session, using a paired t-test, in each of the patient and healthy subject groups. As in previous studies $(8,9)$, the vibration induced errors in amplitude were expressed by the ratios of V/NV movement amplitude. The level of significance was set at an alpha of $P \leq 0.05$ level ( $p$ values are given to three decimal places). Finally, the magnitude of the effect was estimated by calculating Cohen's $d$, where 0.2 is a small magnitude, 0.5 is a medium magnitude, and 0.8 is a large magnitude effect (16). Statistical analyses were performed using commercially available statistical software (Statistica, USA). 


\section{Results}

The results obtained with one PD patient are shown as an example representative of the population, in Figure 2. In the pre-training session, the patient underestimated the amplitude of voluntary ankle dorsiflexion performed, since the movement surpassed the target amplitude $\left(28^{\circ} \pm 7\right.$, mean \pm SD). When vibrations were applied to the GS muscle tendon, the amplitude of the voluntary movement decreased slightly $\left(22^{\circ} \pm 8\right)$ (Fig. $\left.2 \mathrm{~A}\right)$. In the post-training session, the mean movement amplitude decreased, but the movement was nevertheless overestimated $\left(25^{\circ} \pm 2\right)$. The application of mechanical vibration on the GS muscle tendon also induced a reduction in the end point $\left(16^{\circ} \pm 5\right)$, which was larger than in the pre-training session (Fig. 2B). The results are expressed by a V/NV ratio of 0.78 before training that decreased to 0.64 after training.

A

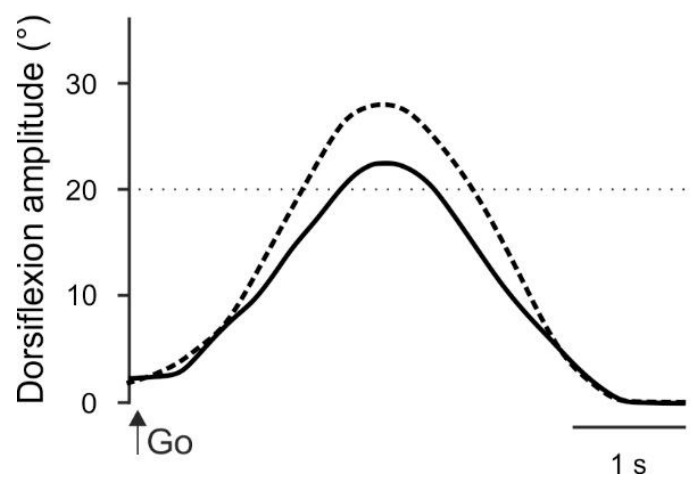

B

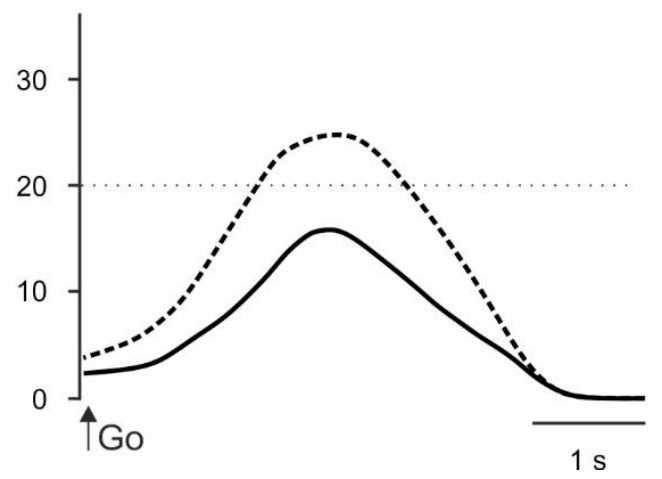

Fig. 2: Effect of the proprioceptive training on vibration-induced movement errors in a patient with Parkinson's disease. The figure illustrates the averaged trajectory of $\mathbf{1 5}$ dorsiflexion movements with (continuous lines) and without (dotted lines) vibratory stimulation applied to the tendon of the Gastrocnemius Soleus muscle, before (A) and after the training (B). The arrow labelled Go indicates the timing of the first auditory cue to begin movement. Note the increase in the difference in amplitude between the two curves after training.

The results obtained for the whole population of PD patients are reported in Fig. 3. The patients were able to make voluntary dorsiflexion movements on proprioceptive guidance only; however, these movements generally exceeded the required amplitude $\left(28.7^{\circ} \pm 2.1\right.$, mean \pm SEM). When mechanical vibration was applied to the GS muscle tendon (V trials) the mean amplitude decreased slightly, but it still overshot the target end point $\left(26.6^{\circ} \pm 1.9\right)$. Moreover, the amplitude of the movements performed during these $\mathrm{V}$ trials did not significantly differ from that measured in the 
absence of vibration ( $\mathrm{NV}$ trials, $\mathrm{t}=1.39, \mathrm{p}=0.196)$. After the training session, $\mathrm{GS}$ vibration caused a significant reduction in the dorsiflexion mean amplitude $(21.1 \pm 1.9)$ as compared to either the amplitude in $\mathrm{V}$ pre-training trials $(\mathrm{t}=3.08, p=0.012, d=1.00)$ or $\mathrm{NV}$ post-training trials $(\mathrm{t}=4.34$, $p=0.001, d=0.94)$. Importantly, the mean amplitude in the non-vibrated trials did not differ significantly between the pre- and post-training sessions.

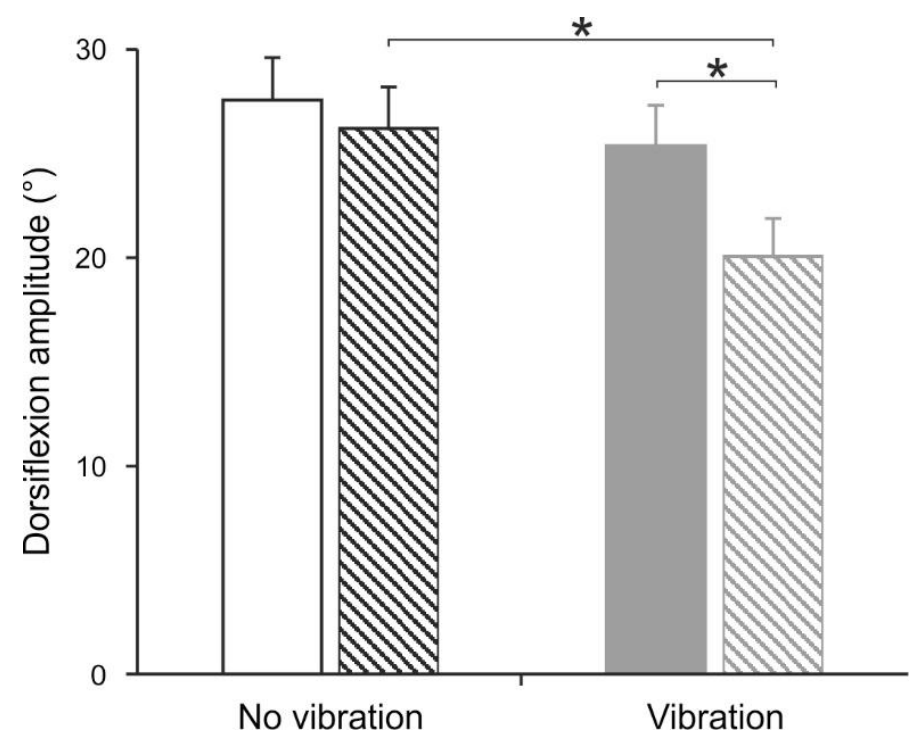

Fig. 3: Mean amplitudes ( \pm SEM) of dorsiflexion movements recorded for the population of patients with Parkinson' disease without (open bar) and with vibratory stimulation (grey bar) applied to the tendon of the Gastrocnemius Soleus muscle. Pretraining are uniform colors and post-training are hashed colors. * Significant difference at $P<0.001$.

The same experiment was run on healthy subjects. On the whole, these age-matched subjects also underestimated the movement amplitude and performed dorsiflexion that reached $26.5^{\circ}( \pm 2.1)$ in the trials without vibratory stimulation. When vibratory stimulation was applied to the tendon of the GS muscle, the mean movement amplitude significantly decreased to $22.2^{\circ} \pm 2.1(\mathrm{t}=6.86, p<0.001$, $d=0.59)$. After the training session, the mean movement amplitude with vibratory stimulation $\left(19.0^{\circ}\right.$ $\pm 1.3)$ was also significantly lower $(\mathrm{t}=9.86, p<0.001, d=1.04)$ than that measured without vibration $\left(23.7^{\circ} \pm 1.4\right)$. Akin to the PD group, the mean amplitude in the non-vibrated trials did not change significantly, as compared to the pre-training sessions.

As in previous studies, the results can be expressed by the V/NV ratio in both populations of subjects (Fig. 4). For PD patients, the ratio decreased significantly from $0.93 \pm 0.04$ in the pre-training to 
$0.81 \pm 0.09$ in the post-training session $(\mathrm{t}=4.91, p<0.001, d=1.01)$, while it remained unchanged in the two sessions $(0.83 \pm 0.04$ vs $0.80 \pm 0.03)$ for the control subjects. Moreover, the ratio reached after training in PD patients was not significantly different to the ones measured in the healthy subjects.

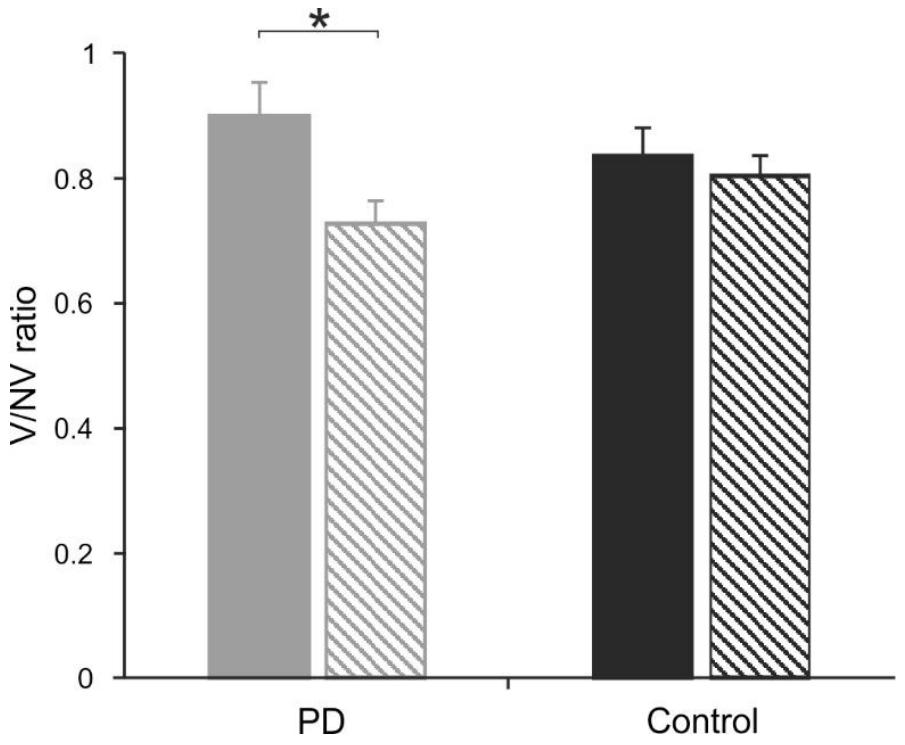

Fig. 4: Mean vibratory/non-vibratory (V/NV) movement amplitude ratios calculated in patients with Parkinson's disease (grey) and healthy subjects (black) in the pre-training (uniform colors) and post-training (hashed colors) sessions. 


\section{Discussion}

\subsection{Assessment of deficits in proprioceptive integration by means of vibration- induced movement errors in Parkinson's patients}

Proprioceptive information arising from muscle spindles provides a major contribution to our movement sense (1) and mechanical vibration applied to muscle tendons is known to activate muscle spindle endings strongly, particularly the primary endings (10). Consequently, applying vibration on the stretched muscle during movement induces an increase in proprioceptive activity (10). In healthy subjects, this increase in muscle spindle activity is interpreted as if the movement was performed at a higher velocity and this leads to a deceleration and reduced amplitude of the voluntary movement, as compared to the desired movement, i.e. a vibration-induced movement error $(11,12)$. We observed this phenomenon in the present population of healthy, older subjects, where dorsiflexion movements performed during vibration of the stretched GS muscle were significantly reduced in amplitude. This was because the movements felt like they were of larger amplitude, as compared to movements performed without vibration.

Conversely, in PD patients, movements performed in the presence of vibration of the stretched muscle did not differ significantly from those performed without vibration. This is consistent with previous studies investigating the effect at the level of the ankle joint (9) and the wrist joint (8). Considering that the peripheral sensory inflow coming from muscles appears to be spared in patients with PD (3), the well-documented proprioceptive abnormalities may be of central origin only (17). This central origin is corroborated by the finding that kinesthetic acuity improves by $20 \%$ in patients receiving deep brain stimulation, after a few months of treatment $(15,18)$, which was also the case for the patients included in the present study. Regarding the probable central origin of the proprioceptive abnormalities in patients with $\mathrm{PD}$, we sought to investigate whether a proprioceptive training based on kinesthetic illusions may improve the processing of proprioceptive inputs and for 
that purpose we evaluated the changes in the amplitude of the vibration-induced movement errors before and after such training.

\subsection{Sensations of illusory movements as a means for reeducation in Parkinson's} patients

Tendon vibration activates muscle spindle primary endings (10) and the vibration-induced muscle proprioceptive message is interpreted, by subjects at rest with their eyes closed, as a movement that would have stretched the vibrated muscle $(1,19)$. The induction of illusory movement has been demonstrated previously to promote rehabilitation, particularly in the recovery of voluntary movements after experimental limb immobilization. Muscle tendon vibration preserves functioning in central sensorimotor networks, which are normally altered by limb immobilization (20). In the same way, we recently showed that a rehabilitation program based on kinesthetic illusions reduces the deleterious effects of gradual motor impairment in patients suffering from muscular dystrophy (21).

The induction of illusory movement is advantageous as a means of training PD patients, since experiencing these sensations requires them to focus their attention on the muscle proprioceptive information, as the processing of these signals is degraded in PD. This is in contrast to training with passive movements, which involves not only muscle afferent feedback, but other movement-related sensory cues such as cutaneous, joint, and articular ones (22,23). Furthermore, using microneurography in healthy subjects, we recently showed that muscle spindle activity was modified by descending processes when subjects focused their attention on imposed movements $(24,25)$. The focusing of attention in patients may thus be a means of optimizing the muscle afferent feedback.

Our proposed rehabilitation program seemed feasible, since it has been shown that vibration-induced illusory movements are normal in PD patients (26). We confirmed here that all the patients experienced sensations of illusory movements of the ankle that were exactly as expected: the illusion 
of ankle dorsiflexion or plantar flexion with vibration applied on GS and TA muscles, respectively. Moreover, the velocity of the sensation was reported to increase when a slight stretching of the vibrated muscle was imposed. Therefore, the patients focused on their proprioceptive information, which was the goal of our training.

\subsection{Increase in vibration-induced movement error following proprioceptive training}

Presently, we showed that proprioceptive training increased the amplitude of the vibration-induced movement error significantly, as compared to pre-training in PD patients. Conversely, the ratio V/NV was unchanged in the population of control age-matched subjects, which allows us to conclude that this was not due to effects related to aging. Furthermore, the dorsiflexion movements performed in the absence of vibration (NV trials) did not differ between the pre- and post-training sessions. Therefore, the decrease in the V/NV ratio after training can be interpreted as a reduction in the amplitude of the movement performed during vibration. These results signify that proprioceptive training changed the processing of proprioceptive inputs in PD patients.

Previous studies have showed clinical and functional benefits in PD patients following a rehabilitation program, designed to have participants focus on proprioceptive feedback during physical exercises (27-29). In these previous findings, the use of proprioceptive cues was reinforced by asking the participants to keep their eyes closed and to focus attention on specific portions of actual exercises. Therefore, the sensory feedback accentuated in these studies might have been from vestibular, cutaneous and/or muscular systems, and the physical exercise may have played a role in the described improvements. In the present study, we showed that specifically targeting the muscle sensory system, the sensitivity of which is known to increase with focusing attention $(24,25)$, is suitable for the rehabilitation of the processing of muscle proprioceptive inputs. Cortical plasticity may allow such sensory input to bypass the dysfunctional basal ganglia, as has been previously suggested (27). Furthermore, we found a significant improvement with a single training session; 
hence more intensive training may produce a greater and/or long-lasting effect, which deserves further investigation.

Impairments in muscle sensory integration is, at least partly, responsible for motor symptoms in PD, such as impaired balance (13) and there is increasing evidence of the beneficial effects of exercise on motor performance in PD patients (30). Therefore, among the rehabilitation programs available, proprioceptive training based on kinesthetic illusions may have a number of benefits: it is neither painful nor fatiguing, and its recreational nature may enhance the patient compliance with the treatment.

To conclude, proprioceptive training appears as a simple means to improve the processing of muscle proprioceptive inputs in PD patients. The duration of the improvement should be evaluated in further experiments, as well as its impact regarding posture and locomotion.

\section{Acknowledgements}

We are grateful to Elia Gomez and Jean-Paul Beaulieu for their help during the preliminary experiments and to Dr Rochelle Ackerley for improving the English. This work was supported by Centre National de La Recherche Scientifique and Aix-Marseille University grants. 


\section{References}

1. Roll JP, Vedel JP. Kinaesthetic role of muscle afferents in man, studied by tendon vibration and microneurography. Exp Brain Res. 1982;47(2):177-90.

2. Windhorst U. Muscle proprioceptive feedback and spinal networks. Brain Res Bull. 2007 Jul 12;73(4-6):155-202.

3. Hagbarth KE, Wallin G, Löfstedt L, Aquilonius SM. Muscle spindle activity in alternating tremor of Parkinsonism and in clonus. J Neurol Neurosurg Psychiatr. 1975 Jul;38(7):636-41.

4. Maschke M, Gomez CM, Tuite PJ, Konczak J. Dysfunction of the basal ganglia, but not the cerebellum, impairs kinaesthesia. Brain. 2003 Oct;126(Pt 10):2312-22.

5. Konczak J, Krawczewski K, Tuite P, Maschke M. The perception of passive motion in Parkinson's disease. J Neurol. 2007 May;254(5):655-63.

6. Lee D, Henriques DY, Snider J, Song D, Poizner H. Reaching to proprioceptively defined targets in Parkinson's disease: effects of deep brain stimulation therapy. Neuroscience. 2013 Aug 6;244:99-112.

7. Seiss E, Praamstra P, Hesse CW, Rickards H. Proprioceptive sensory function in Parkinson's disease and Huntington's disease: evidence from proprioception-related EEG potentials. Exp Brain Res. 2003 Feb;148(3):308-19.

8. Rickards C, Cody FW. Proprioceptive control of wrist movements in Parkinson's disease. Reduced muscle vibration-induced errors. Brain. 1997 Jun;120 ( Pt 6):977-90.

9. Khudados E, Cody FW, O'Boyle DJ. Proprioceptive regulation of voluntary ankle movements, demonstrated using muscle vibration, is impaired by Parkinson's disease. J Neurol Neurosurg Psychiatr. 1999 Oct;67(4):504-10.

10. Roll JP, Vedel JP, Ribot E. Alteration of proprioceptive messages induced by tendon vibration in man: a microneurographic study. Exp Brain Res. 1989;76(1):213-22.

11. Capaday C, Cooke JD. The effects of muscle vibration on the attainment of intended final position during voluntary human arm movements. Exp Brain Res. 1981;42(2):228-30.

12. Cody FW, Schwartz MP, Smit GP. Proprioceptive guidance of human voluntary wrist movements studied using muscle vibration. J Physiol (Lond). 1990 Aug;427:455-70.

13. Vaugoyeau M, Viel S, Assaiante C, Amblard B, Azulay JP. Impaired vertical postural control and proprioceptive integration deficits in Parkinson's disease. Neuroscience. 2007 May $11 ; 146(2): 852-63$.

14. Vaugoyeau M, Azulay J-P. Role of sensory information in the control of postural orientation in Parkinson's disease. J Neurol Sci. 2010 Feb 15;289(1-2):66-8.

15. Maschke M, Tuite PJ, Pickett K, Wächter T, Konczak J. The effect of subthalamic nucleus stimulation on kinaesthesia in Parkinson's disease. J Neurol Neurosurg Psychiatr. 2005 Apr;76(4):569-71. 
16. Cohen J. A power primer. Psychol Bull. 1992 Jul;112(1):155-9.

17. Conte A, Khan N, Defazio G, Rothwell JC, Berardelli A. Pathophysiology of somatosensory abnormalities in Parkinson disease. Nat Rev Neurol. 2013 Dec;9(12):687-97.

18. Wagle Shukla A, Moro E, Gunraj C, Lozano A, Hodaie M, Lang A, et al. Long-term subthalamic nucleus stimulation improves sensorimotor integration and proprioception. J Neurol Neurosurg Psychiatr. 2013 Sep;84(9):1020-8.

19. Goodwin GM, McCloskey DI, Matthews PB. Proprioceptive illusions induced by muscle vibration: contribution by muscle spindles to perception? Science. 1972 Mar 24;175(28):1382 4.

20. Roll R, Kavounoudias A, Albert F, Legré R, Gay A, Fabre B, et al. Illusory movements prevent cortical disruption caused by immobilization. NeuroImage. 2012 May 12;62(1):510-9.

21. Ribot-Ciscar E, Milhe-De Bovis V, Aimonetti J-M, Lapeyssonnie B, Campana-Salort E, Pouget $\mathrm{J}$, et al. Functional impact of vibratory proprioceptive assistance in patients with facioscapulohumeral muscular dystrophy. Muscle Nerve. 2015 Nov;52(5):780-7.

22. Aimonetti J-M, Roll J-P, Hospod V, Ribot-Ciscar E. Ankle joint movements are encoded by both cutaneous and muscle afferents in humans. Exp Brain Res. 2012 Aug;221(2):167-76.

23. Proske U, Gandevia SC. The proprioceptive senses: their roles in signaling body shape, body position and movement, and muscle force. Physiol Rev. 2012 Oct;92(4):1651-97.

24. Hospod V, Aimonetti J-M, Roll J-P, Ribot-Ciscar E. Changes in human muscle spindle sensitivity during a proprioceptive attention task. J Neurosci. 2007 May 9;27(19):5172-8.

25. Ribot-Ciscar E, Hospod V, Roll J-P, Aimonetti J-M. Fusimotor drive may adjust muscle spindle feedback to task requirements in humans. J Neurophysiol. 2009 Feb;101(2):633-40.

26. Moore A. Vibration-induced illusions of movement are normal in Parkinson's disease: implications for the mechanism of the movement disorder. In: Neural mechanisms in disorders of movement. London: John Libbey; 1989. p. 307-11.

27. Sage MD, Almeida QJ. Symptom and gait changes after sensory attention focused exercise vs aerobic training in Parkinson's disease. Mov Disord. 2009 Jun 15;24(8):1132-8.

28. Sage MD, Almeida QJ. A positive influence of vision on motor symptoms during sensory attention focused exercise for Parkinson's disease. Mov Disord. 2010 Jan 15;25(1):64-9.

29. Lefaivre SC, Almeida QJ. Can sensory attention focused exercise facilitate the utilization of proprioception for improved balance control in PD? Gait Posture. 2015 Feb;41(2):630-3.

30. Ebersbach G. Parkinson disease: Exercise matters in patients with PD-another piece of evidence. Nat Rev Neurol. 2015 Jan;11(1):9-10. 
Table 1 Patient characteristics

\begin{tabular}{ccccccc}
\hline Patient & $\begin{array}{c}\text { Age } \\
\text { (years) }\end{array}$ & Gender & $\begin{array}{c}\text { More } \\
\text { affected } \\
\text { foot }\end{array}$ & $\begin{array}{c}\text { Disease } \\
\text { duration } \\
\text { (years) }\end{array}$ & $\begin{array}{c}\text { STN-DBS } \\
\text { duration } \\
\text { (months) }\end{array}$ & $\begin{array}{c}\text { UPDRS III } \\
\text { on ont }\end{array}$ \\
\hline 1 & 62 & F & R & 16 & 6 & 15 \\
2 & 70 & M & R & 10 & 6 & 10 \\
3 & 56 & F & L & 11 & 6 & 7 \\
4 & 64 & M & L & 7 & 12 & 9 \\
5 & 61 & F & L & 7 & 36 & 13 \\
6 & 66 & F & L & 5 & 3 & 7 \\
7 & 73 & F & L & 11 & 36 & 20 \\
8 & 63 & M & L & 10 & 12 & 13 \\
9 & 65 & M & L & 13 & 12 & 17 \\
10 & 50 & M & L & 9 & 3 & 9 \\
11 & 65 & F & R & 9 & 36 & 6
\end{tabular}

t.With dopa and during stimluation on

STN-DBS: subthalamic nucleus deep brain stimulation

UPDRS: unified Parkinson disease rating scale 